\title{
Documenting Indigenous Knowledge to Identify and Understand the Stressors of Muskoxen (Ovibos moschatus) in Nunavut, Canada
}

\author{
Juliette Di Francesco, ${ }^{1,2}$ Andrea Hanke, ${ }^{1}$ Terry Milton, ${ }^{3}$ Lisa-Marie Leclerc, ${ }^{3}$ Kugluktuk Angoniatit Association, ${ }^{4}$ \\ Craig Gerlach ${ }^{5}$ and Susan Kutz ${ }^{1}$
}

(Received 25 September 2021; accepted in revised form 21 April 2021)

\begin{abstract}
Indigenous knowledge provides valuable information on wildlife health and ecology, contributing to a broader understanding of the patterns and phenomena observed. Muskoxen (Ovibos moschatus), an important species for the subsistence and culture of Inuit communities in the Arctic, are increasingly exposed to diverse stressors linked to rapid climate change and other anthropogenic changes. Identifying and understanding these stressors and their impacts on muskoxen will inform management, health monitoring, and future research. To achieve this understanding, we documented Indigenous knowledge through seven semi-structured small group interviews, each involving two to three purposely chosen muskox harvesters in Kugluktuk, Nunavut, Canada to (1) establish the characteristics of healthy muskoxen, (2) determine the factors considered to impact muskoxen, and (3) understand, from an Indigenous knowledge perspective, the results from a study on the sex, seasonal, and annual patterns of glucocorticoids (described as "stress hormones" for the purposes of the interviews) in muskox hair. Key outcomes include (1) a more holistic understanding of muskox health and what it encompasses, (2) recognition and exploration of a rich One Health perspective expressed by participants around factors influencing muskoxen in a changing world and highlighting the multiple socioecological connections, and (3) a broader comprehension of the glucocorticoid (stress) patterns measured in muskox hair, the various factors that influence them, and their interrelations. This study represents a meaningful advancement in the process of actively involving communities at all steps of the research and highlights the important contributions Indigenous knowledge can offer to the complex field of wildlife endocrinology research.
\end{abstract}

Key words: muskox; Ovibos moschatus; wildlife; stress; Indigenous knowledge; Arctic

RÉSUMÉ. Les connaissances autochtones permettent d'obtenir de précieux renseignements sur la santé et l'écologie de la faune sauvage, ce qui mène à une plus grande compréhension des tendances et des phénomènes observés. Le bœuf musqué (Ovibos moschatus), une espèce importante pour la subsistance et la culture des communautés inuites de l'Arctique, est de plus en plus souvent exposé à divers facteurs de stress liés au changement climatique rapide et à d'autres changements anthropiques. La détermination et la compréhension de ces facteurs de stress et de leurs incidences sur le bœuf musqué permettront d'améliorer la gestion des populations et la surveillance de la santé, tout en ouvrant des perspectives pour la recherche. Pour ce faire, nous avons documenté les connaissances autochtones au moyen de sept entrevues semi-structurées réalisées en petits groupes. Chacune de ces entrevues incluait deux à trois chasseurs de bœufs musqués choisis avec soin à Kugluktuk, au Nunavut, Canada, dans le but 1) d'établir les caractéristiques des bœufs musqués en bonne santé, 2) de déterminer les facteurs considérés comme ayant une incidence sur les bœufs musqués, et 3 ) de comprendre, du point de vue des connaissances autochtones, les résultats d'une étude portant sur les variations dans les concentrations de glucocorticoïdes (décrits comme les « hormones de stress » durant les entrevues) mesurées dans les poils des bœufs musqués, en fonction du sexe, des saisons et des années. Parmi les principaux résultats, notons 1) une compréhension plus holistique de la santé du bœuf musqué et de ce qu'elle comprend, 2) la reconnaissance et l'exploration d'une riche perspective reposant sur la notion «Une seule santé » exprimée par les participants au sujet des facteurs influençant les bœufs musqués dans un monde en pleine évolution, tout en faisant ressortir les multiples liens socioécologiques, et 3) une plus grande compréhension des variations dans les concentrations de glucocorticoïdes (stress) mesurées dans les poils de bœufs musqués, des divers facteurs qui les influencent et des liens qui existent entre ces facteurs. Cette étude apporte des avancées considérables sur le plan du processus visant à faire participer activement les communautés à toutes les étapes de la recherche. Elle fait également ressortir l'apport important des connaissances autochtones dans le domaine complexe de la recherche endocrinologique de la faune sauvage.

${ }^{1}$ Department of Ecosystem and Public Health, Faculty of Veterinary Medicine, University of Calgary, 3280 Hospital Drive NW, Calgary, Alberta T2N 4Z6, Canada

${ }^{2}$ Corresponding author: Centre d'Epidémiologie et de Santé Publique des Armées (CESPA), Camp de Sainte Marthe, BP 40026 Marseille Cedex 02, France; juliette.difrancesco@ucalgary.ca

${ }^{3}$ Department of Environment, Government of Nunavut, PO Box 377, Kugluktuk, Nunavut X0B 0E0, Canada

${ }^{4}$ Kugluktuk, Nunavut X0B 0E0, Canada

${ }^{5}$ School of Architecture, Planning and Landscape, University of Calgary, 2500 University Drive NW, Calgary, Alberta T2N 1N4, Canada

(c) The Arctic Institute of North America 
INDIGENOUS KNOWLEDGE OF MUSKOX STRESSORS • 419

Mots clés : bœuf musqué; Ovibos moschatus; faune sauvage; stress; connaissances autochtones; Arctique

Traduit pour la revue Arctic par Nicole Giguère.

\section{INTRODUCTION}

Conservationists and ecologists are increasingly focused on understanding physiological stress responses in wildlife, including their causes and consequences and how they may be affected by various ecological changes and environmental challenges (Bonier et al., 2009; Busch and Hayward, 2009; Dantzer et al., 2014; Koren et al., 2019). The conventional approach has been to measure glucocorticoids, as these hormones are important mediators of the physiological stress response (Romero and Butler, 2007), and to examine associations with potential stressors such as anthropogenic disturbance and habitat alterations (Mastromonaco et al., 2014; Fourie et al., 2015; Ewacha et al., 2017). Identifying stressors and understanding their impacts on different wildlife species are all the more important now, especially in rapidly changing and sensitive environments such as the Arctic, where climate change is occurring at an unprecedented pace, and anthropogenic activities are accelerating (Post et al., 2013; AMAP, 2017).

Approaching complex conservation problems with both scientific and Indigenous or local knowledge is an increasingly recognized strategy (Huntington, 2011; Kutz and Tomaselli, 2019). However, to date, Indigenous and local knowledge systems have rarely been taken into account to identify and assess the impacts of stressors on wildlife. Indigenous knowledge (IK) is "a cumulative body of knowledge and beliefs handed down through generations by cultural transmission about the relationship of living beings (including humans) with one another and with their environment" (Gadgil et al., 1993:151). Local knowledge is defined as "a local body of knowledge, not associated with aboriginal ethnicity, but characterized by both historical and contemporary knowledge acquired through extensive observation of the environment and its species" (Tomaselli et al., 2018b:338), and therefore encompasses but is not limited to IK. Indigenous and local knowledge are constantly evolving from the experience and observations of their holders and provide information about historical conditions and local processes at a detailed scale (Gadgil et al., 1993; Usher, 2000).

Scientific knowledge (SK) is often considered the gold standard for conservation action, driven as it is by specific research questions that rely on replicable quantitative measures. However, data collection, even though systematic, tends to be circumscribed in time and space, particularly in remote areas such as the Arctic, where financial, human capacity, and logistical barriers are obstacles to cyclical long-term monitoring (Lubin and Massom, 2006; Kutz and Tomaselli, 2019). In combination, scientific and Indigenous or local knowledge may yield a result that circumvents some of the constraints, limitations, and biases inherent within each knowledge system (Brook et al., 2009; Tomasini, 2018; Kutz and Tomaselli, 2019; Peacock et al., 2020) with the potential to arrive at a much richer and deeper understanding of ecological systems (Sefa Dei et al., 2000; Robinson and Wallington, 2012; Kutz and Tomaselli, 2019; Baker and Constant, 2020). More specifically for IK, approaches that include the consideration of IK are responsive to mandates set out by land claims agreements (e.g., INAC, 1984, 1993) and calls for Indigenous sovereignty in research (Schnarch, 2004; ITK and NRI, 2006; ITK, 2018).

Indigenous and local knowledge are now recognized as valuable sources of information on wildlife health and ecology and have increasingly been used to advance this field of research (Kutz and Tomaselli, 2019). With respect to wildlife ecology, Dene and Métis knowledge was documented concomitantly with the analysis of genetic data to describe caribou (Rangifer tarandus) population structure and variation in the Sahtu Region, Northwest Territories (NWT), Canada, and to generate insights into the evolutionary histories that likely contributed to such population differentiation (Polfus et al., 2016). The knowledge of Sámi reindeer herders was documented in Sweden and Norway to characterize snow types and profiles, to understand how reindeer ( $R$. t. tarandus) are affected by various snow conditions, and to evaluate the potential impacts that long-term changes in snow and ice conditions will have on reindeer herding (Riseth et al., 2011; for other examples, see Huntington et al., 2004; Kumpula et al., 2011; Laforest et al., 2018). With respect to wildlife health, Indigenous and local knowledge documented in the Nunavut community of Ekaluktutiak described population trends and the health status of muskoxen (Ovibos moschatus) and caribou in the area (Tomaselli et al., 2018b). Participants' observations provided insights into previously undocumented mortality events and possible diseaseassociated causes of population decline (Tomaselli et al., 2018b). These examples demonstrate that systematically documenting Indigenous or local knowledge can lead to an expanded understanding of wildlife health and ecology.

Muskoxen, a taxonomically unique and iconic ungulate species in the Canadian Arctic, are an essential component of the local ecosystem and are important for the subsistence, economy, and cultural identity of Inuit communities that have depended on them for generations (Lent, 1999; Tomaselli et al., 2018a). Muskoxen are increasingly exposed to a wide diversity of stressors linked to rapid climate change and other anthropogenic changes (AMAP, 2017; Kutz et al., 2017; Cuyler et al., 2020). The effects of these stressors are likely cumulative, extremely complex, and remain poorly understood. Muskoxen are highly adapted to life in the Arctic, but recent substantial and ongoing population 
declines in the western Canadian Arctic Archipelago suggest that they are particularly vulnerable to a shifting environment (Kutz et al., 2017; Cuyler et al., 2020).

Cortisol levels (the dominant glucocorticoid in muskoxen; Koren et al., 2012) have been reliably measured in the hair of muskoxen, with their interpretation solely based on the current state of SK on wildlife endocrinology and muskox ecology (Di Francesco et al., 2017). Identifying the stressors that specifically affect muskoxen and understanding their impacts more holistically will better inform endocrinological studies, population management, current health monitoring programs, and future research directions.

This research documented IK with the aim to identify potential stressors of muskoxen and to gain a better understanding of their effects on this species. The specific objectives were to (1) document IK on the characteristics harvesters use to identify whether a muskox is healthy, (2) document IK on the factors that affect muskoxen in a positive or negative way, their importance and impacts, when they occur throughout the year, and how they have changed over time, and (3) understand, from an IK perspective, the results from a previously published study on hair cortisol levels measured in locally harvested wild muskoxen (Di Francesco et al., 2017).

\section{METHODS}

\section{Study Area}

The study took place in the hamlet of Kugluktuk, in the Kitikmeot region of Nunavut, Canada (Fig. 1). The population in 2016 was 1491, the majority of whom are Inuit (approximately 90\%; Statistics Canada, 2016). Muskoxen, caribou, and moose (Alces alces) are the three terrestrial ungulate species found in the area and harvested by residents of the community. Three types of hunts can be distinguished based on their purpose: (1) subsistence hunts, in which community residents harvest the animal for their own consumption or for sharing among a wider network of kin and community relations; (2) community hunts, in which local harvesters are hired by the Kugluktuk Angoniatit Association (local hunters and trappers' organization) to harvest meat for residents in need; and (3) guided hunts (locally referred to as "sport hunts"), in which males are selectively harvested for their trophy characteristics by guided hunters. Muskoxen are typically hunted by Kugluktuk residents in three different management zones: MX-07 (the Nunavut part of Victoria Island), MX-09 (the mainland west of the Coppermine River), and MX-11 (the mainland east of the Coppermine River) (Department of Environment, Government of Nunavut, 2018).

Since 2014, Kugluktuk has actively participated in a regional hunter-based muskox health-monitoring program, which is a partnership among the communities of Kugluktuk, Ekaluktutiak, and Ulukhaktok, government biologists, guided hunting organizations, and academic researchers. Many of the samples analyzed as part of the previously published study on hair cortisol levels in wild muskoxen were collected through this hunter-based sampling program (Di Francesco et al., 2017).

\section{Study Overview}

We consulted with the Kugluktuk Angoniatit Association in April 2018 to discuss community interests in this study in the context of the ongoing hunter-based sampling program. We then did small group interviews in January and February 2019 and subsequently hosted validation sessions in January and February 2020. Preliminary results from the small group interviews were presented in January 2020 during the annual general meeting of the Kugluktuk Angoniatit Association and final results will be reported in the general meeting in 2021.

Participation in the study was voluntary and interviewees were free to withdraw at any time. Participants were local muskox experts and received honoraria for their time in agreement with the standards established by the Kitikmeot Inuit Association. The research was approved both by the Conjoint Faculties Research Ethics Board of the University of Calgary (REB16-1214) and the Nunavut Research Institute (Scientific Research License No. 04002 19R-M). After consulting with the Kugluktuk Angoniatit Association, participants who were fluent in both English and Inuinnaqtun provided translation support during both the small group interviews and the validation sessions.

\section{Interviews}

Here, we use traditional Inuit knowledge (TIK) instead of IK as study participants unanimously agreed on this term to refer to their knowledge.

Format and Participant Recruitment: We initially documented TIK through seven semi-structured small group interviews, each involving two to three muskox harvesters who knew each other. To recruit participants with extensive hunting experience and knowledge about muskoxen and the land, individuals were either recommended by the Kugluktuk Angoniatit Association or the local government wildlife officers (i.e., purposive sampling), or recruited by snowball sampling, with participants identifying additional informants (Green and Thorogood, 2014; Armitage and Kilburn, 2015). Many of the recruited participants were actively taking part in the hunter-based sampling program. To facilitate equal participation, and because the experience, knowledge, and perspectives of participants were likely to differ based on their age, groups of Elders and non-Elders were formed (Green and Thorogood, 2014; Roller and Lavrakas, 2015). All participants included in the Elder groups confirmed that they self-identified as Elders. J. Di Francesco was the study interviewer and was assisted by either A. Hanke or T. Milton during the interviews. 


\section{Study Area}

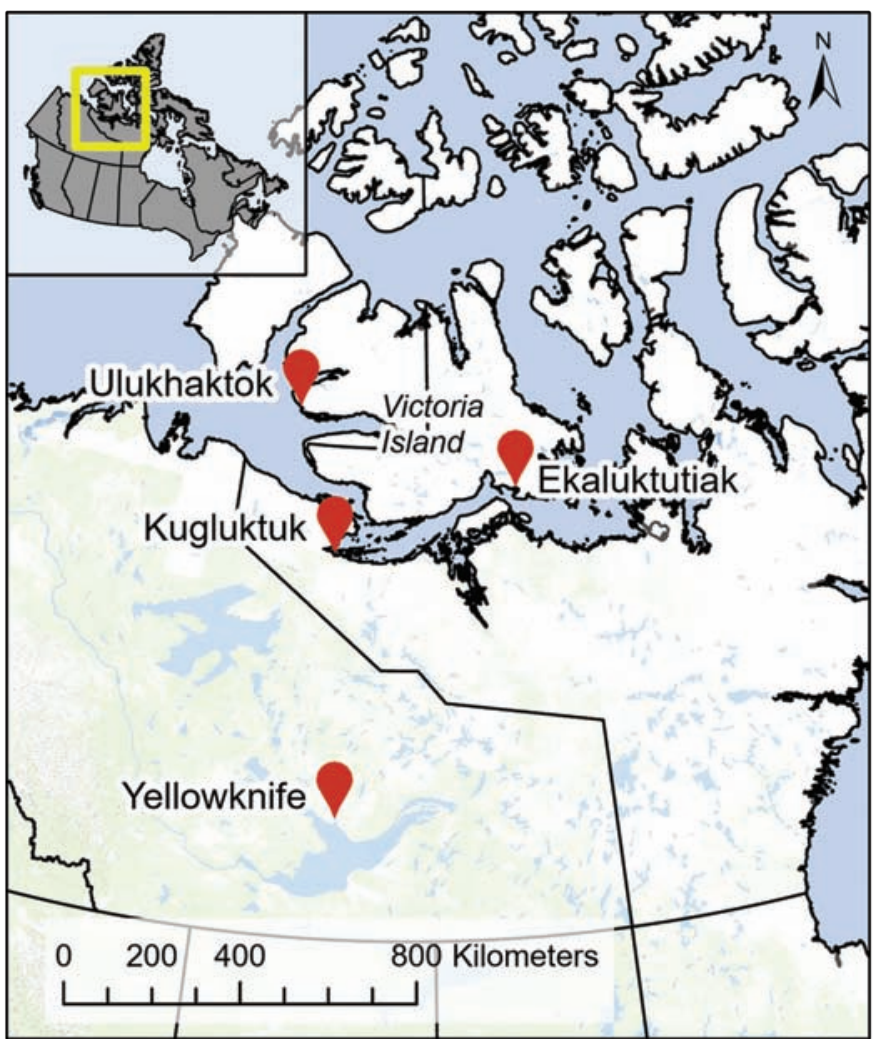

FIG. 1. Location of the communities of Kugluktuk and Ekaluktutiak in Nunavut and Ulukhaktok and the town of Yellowknife in the Northwest Territories.

Sixteen men and one woman participated in the small group interviews. Ten were Elders (median age $=62$ years; range $=51-86$ years) and seven were non-Elders (median age $=36$ years; range $=22-43$ years). All participants selfidentified as Inuit.

Interviewing Process: To document TIK on the characteristics of a healthy muskox, we asked participants "how they recognize that a muskox is healthy" and "what are the characteristics that they look for." To document TIK on the factors that affect muskoxen in a positive or negative way, we first focused the discussion on the negative and then the positive factors. We formulated this question broadly instead of using the term "stress" so as to keep our approach holistic rather than reductionist, and with the goal of capturing a greater breadth of participant knowledge. Also, this decision is responsive to discrepancies between IK and SK ontologies, thereby creating space for diverse ways of knowing within this study (Wilson, 2008; Kovach, 2009). Consequently, some of the factors presented in the results may not be direct "stressors" of muskoxen, but rather are elements that would impact them in general or indirectly. In the interview phase, we employed different strategies to engage participants and facilitate discussion. As a starting point, each group was asked to show on a yearly calendar when muskoxen calve, mate, and when males fight. For the factors having a negative or positive impact on muskoxen, participants were also asked to indicate the monthly occurrence of these factors on the calendar and their temporal variability over the broader timescales of participants' experiences across a 70 -year timeline. During the last section of the interview, participants were asked to interpret the results from a previously published study on hair cortisol levels measured in locally harvested wild muskoxen (Di Francesco et al., 2017). To do this, the interviewer presented each major finding and invited discussion. Findings included (1) higher hair cortisol levels in males than in females, (2) higher hair cortisol concentrations in the fall and winter than in the summer, and (3) yearly variations, with an increase in hair cortisol levels between 2013 and 2015 and no significant difference between 2015 and 2016 (Di Francesco et al., 2017). For the purposes of presenting the Di Francesco et al. (2017) research to the participants, the term "stress" was substituted for "hair cortisol."

Analytical Framework: All interviews were audiorecorded and then fully transcribed by J. Di Francesco. T. Milton, an Inuk resident of the community familiar with the cultural context and place names, verified the accuracy of all transcripts. These were subsequently analyzed with NVivo software (QSR International, 2018) using thematic content analysis to identify themes in the participants' accounts (Green and Thorogood, 2014). More specifically, holistic and in vivo coding were first used to identify broad categories, preserving the participants' words where appropriate, and were then followed by descriptive coding and subcoding, as this allowed for the identification of more detailed subcategories (Saldaña, 2013). To ensure the validity of the coding process, coding was done independently by J. Di Francesco and A. Hanke, who then developed a common coding scheme, which was subsequently applied to all transcripts and validated using one of the interviews to verify intercoder reliability (Roller and Lavrakas, 2015).

\section{Validation Process}

The information documented during the small group interviews was summarized and presented back to the community in validation sessions to confirm, refine, modify, or clarify where needed. These sessions included many of the original interviewees, as well as new participants who had not been formally interviewed previously. Five sessions, each including two to six participants grouped by Elders and non-Elders, and one drop-in session, where individuals could come in and provide feedback, were conducted.

Nineteen people ( 2 women and 17 men) attended the validation sessions (one individual attended a drop-in session), 14 of whom had participated in the original small group interviews. Ten were Elders (median age $=68.5$ years; range $=54-87$ years) and nine were nonElders (median age $=34$ years; range $=25-44$ years). All participants self-identified as Inuit. 
To rank and determine the relative importance of the characteristics used by harvesters to establish whether a muskox is healthy, we organized a "dot-voting" activity involving all the characteristics brought up during the small group interviews and any new ones added during particular validation sessions (e.g., Gittelsohn et al., 2010; Ferrell et al., 2014). Participants were given 15 dots and instructed to place between zero and three dots next to each characteristic depending on the importance they attributed to it (i.e., $0=$ low importance to $3=$ high importance). The relative importance of each characteristic then corresponded to the total percentage of dots placed next to it by participants during the dot-voting activities. During the validation sessions, some groups added new characteristics, which were included in the exercise for those groups.

All factors brought up during the initial interviews as affecting muskoxen were presented to the participants for feedback, and participants were asked if anything was missing. The same process was followed to validate the findings from the interpretation of the hair cortisol results. To build the final yearly calendars, we presented those summarizing the initial interviews and adjusted where necessary based on validation group feedback.

\section{RESULTS}

\section{Characteristics of a Healthy Muskox}

Participants indicated that, through their knowledge and experience, they can tell which muskoxen are healthy: "How we recognize are the animals, if they're healthy or stressed, we learn to read them because that's how we were brought up. From a young age, we've been going out hunting with our Elders ... and, you know, I learned a lot from all the Elders." Participants identified external and internal characteristics that they assess before shooting an animal and during butchering, respectively, to determine if a muskox is healthy.

The two most important external characteristics identified were body shape (16.5\% of dots), indicating that the animal is in good body condition, and good quality skin and fur ( $16.2 \%$ of dots). A healthy muskox has a nice, shiny and darker-colored coat, along with a rounded rump. Harvesters also looked for large herd size (12.1\% of dots) as loners are often (but not always) older or less healthy muskoxen that have been left behind from the herd. Other important characteristics were the absence of limping and lumps on the legs (11\% of dots) and the animal's behavior (10.7\% of dots). Healthy muskoxen are more alert, react more quickly, and run away when approached. They are also capable of defending themselves and have good body movements. One participant stated that "when they're really healthy, they prance, they almost prance." Finally, healthy muskoxen have good speed and endurance ( $7.7 \%$ of dots), whereas "the poor muskox would get behind when running." Body size and horns were brought up during the small group interviews as indicators of the types of animals (young animals or medium-size females) that have tender meat, but received low priority during the dot-voting for what identifies a healthy muskox ( $4.4 \%$ and $3.7 \%$ of dots, respectively).

While butchering, participants would examine all the internal organs to determine if the animal is healthy, but mentioned focusing mostly on the lungs ( $9.2 \%$ of dots) and joints $(8.5 \%$ of dots). They would look for clear fluid when cutting the joints and would assess the size, color, amount of lungworms, presence of lumps, and adherence to the ribcage when examining the lungs.

Two validation groups mentioned that they also evaluate the color and texture of the liver, as well as the occurrence of small, clear, fluid-filled cysts $(3.3 \%$ of the dots of these two groups). The appearance of the meat was of very high importance as an indicator of health in one validation group (i.e., $20 \%$ of this group's dots were placed on this characteristic), and participants described observing a gellike substance in the layers of the meat in really stressed muskoxen. Because the liver was brought up later in the validation sessions by only two groups and meat by only one group, they were only incorporated into the dot-voting for those groups.

\section{Positive and Negative Factors Affecting Muskoxen}

Participants repeatedly alluded to the changing world. Within this overarching theme, we classified the factors that participants indicated as affecting muskoxen into three broad interlinked categories: the "physical environment," which includes weather and climatic factors; the "biological environment," which comprises plants and animals; and the "human-muskox relationships," which encompass anthropogenic elements and disturbances (Fig. 2).

We summarized the timing of key life history events (i.e., calving, mating, and males fighting) as indicated by participants on a yearly calendar (Fig. 3a). Interviewees reported observations of male muskoxen fighting all year round, with early August to mid-November being a period of increased fighting and competition between males due to mating. During the rest of the year, there were more typically "practice" battles: "There's a difference between fighting and learning how to fight. These are mostly going to be young punks, ... whereas this [pointing to August to mid-November] is real fighting, mating." Calving was described to occur from March to mid-June, with the majority of the births observed in April, and then mating from July to mid-November.

Physical Environment: Interviewees identified that climate warming and precipitation have both positive and negative impacts on muskoxen, while other aspects of the physical environment, including smoke from forest fires or volcanic eruptions, high snow depth or hardness, slush, muddy terrain, and thawing permafrost, have only negative effects (Fig. 2). The seasonal timing of some of these factors is illustrated (Fig. 3b). 


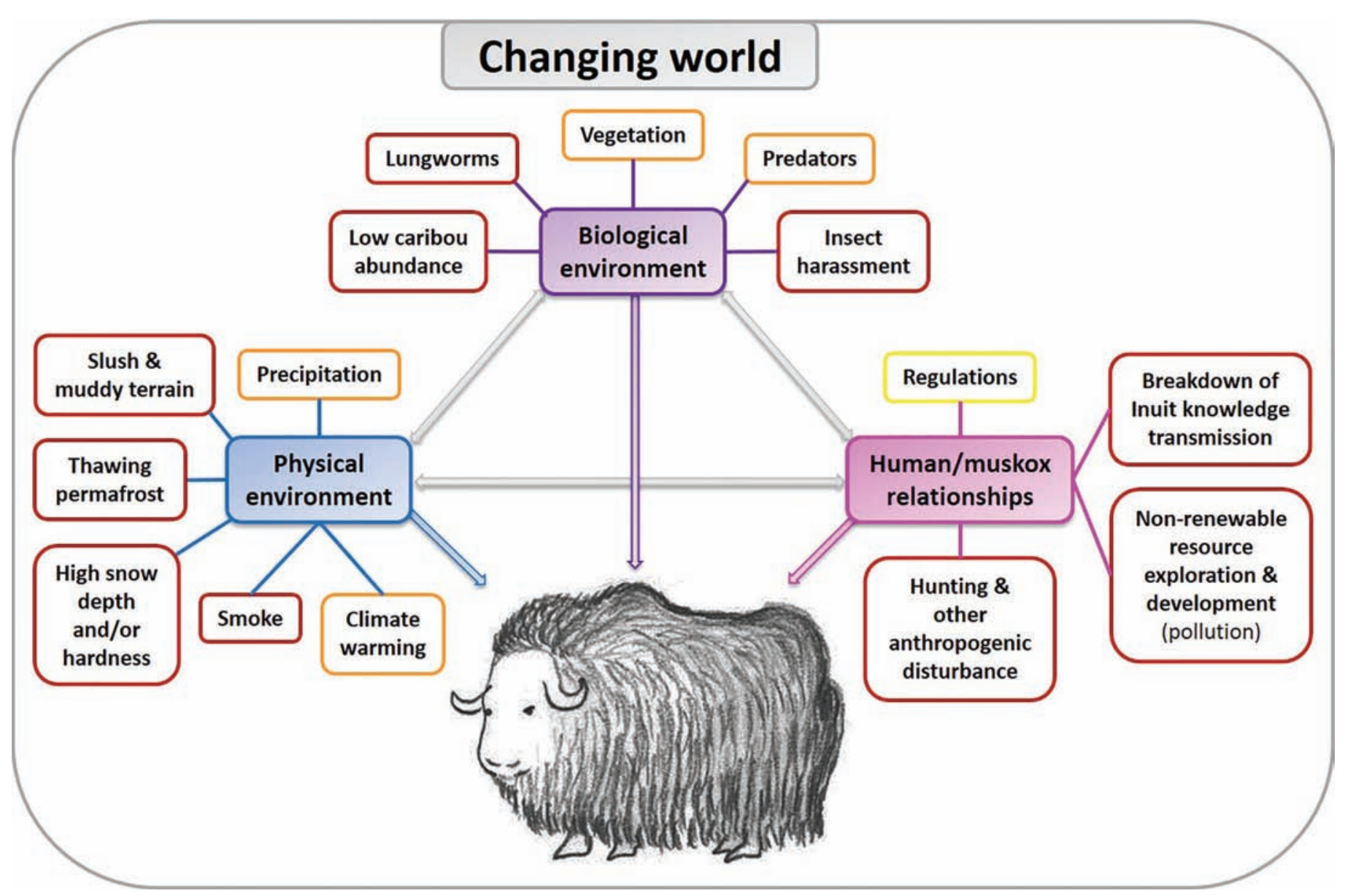

FIG. 2. Factors affecting muskoxen negatively (red), positively (yellow) or both negatively and positively (orange) (muskox drawing by Jayninn Yue).

All participants reported a rise in air temperatures, particularly during the summer, since the $1980 \mathrm{~s}-90 \mathrm{~s}$. Most thought that warmer temperatures increased calf survival; however, one interviewee added that the decreased amount of snow makes it easier for predators to go after muskoxen, especially the newborns: "It probably gives them a better chance because they don't get the extreme cold temperatures right off the bat when they're still small and still developing their hide. And they got easier access to food and more growth of better food. So yeah, it might, but at the same time, it's the perfect chance for a predator too. There's no deep snow to get left behind in."

Regarding the effect of high heat, some interviewees thought that muskoxen are able to cope fairly well with the heat and that their fur contributes to keeping them cool. They would remain active, continue feeding normally, and generally stay near water sources where the air is windier and cooler. By contrast, other participants explained that muskoxen are sensitive to the heat, their thick and dark fur rendering them particularly vulnerable: "It must suck being a muskox in that thick fur during the summer!" This would cause them to move around less, spend more time lying down, and become easier prey. One interviewee described: "They get left behind, they get all sluggish, they won't run. Anything could just walk in and get them. They don't have the energy; they're sweating too much." Another participant mentioned that it was the long periods of high heat (i.e., a couple of weeks) that stress muskoxen. A few participants thought that the longer summers and warmer temperatures may confuse the animals and delay the start of the rut, while others had either not observed or disagreed with this idea. Some participants did not express an opinion as they rarely observed muskoxen during the summer.

Smoke from forest fires occurring in southern Canada was mentioned to negatively affect muskoxen. Although none of the participants had directly observed the effects of smoke on muskoxen, many thought that they would be impacted and that their big lungs, particularly when infected by lungworms, would render them vulnerable. Two validation session groups brought up distant volcanic eruptions that would also cause the release of thick smoke and ash in the air and might affect the vegetation and animals.

Several participants thought that high snow hardness due to temperature fluctuations causing thaw-freeze cycles or mainly to freezing rain (i.e., rain-on-snow events) negatively impacted muskoxen through difficulties in accessing their food. Such circumstances occur only occasionally and their timing, location, and importance varies among years, but their effects are highest if they happen in the fall or spring. Several participants did not think that snow hardness impacted muskoxen substantially as they tend to stay away from the highly affected areas: 
(a) Life events

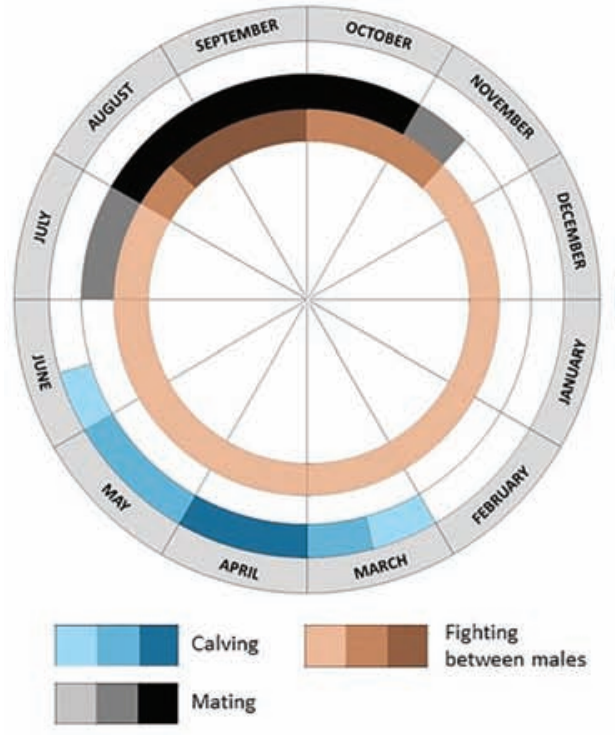

(b) Physical environment

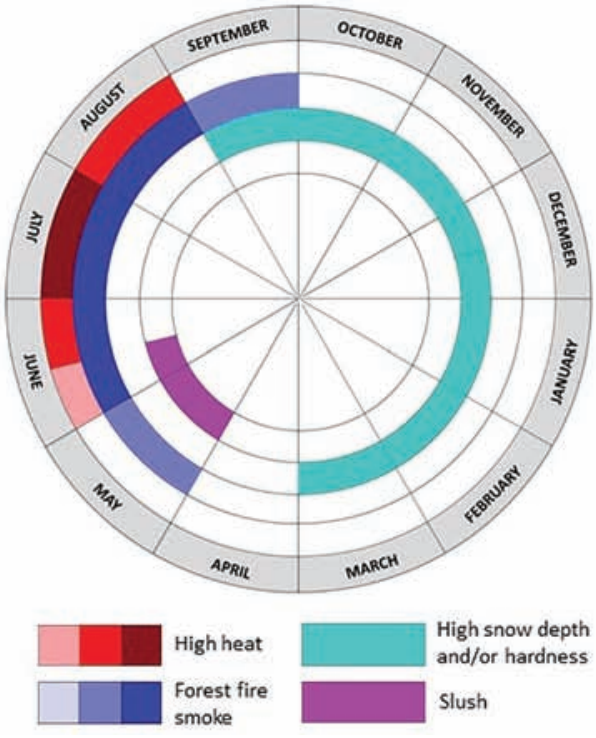

(c) Biological environment

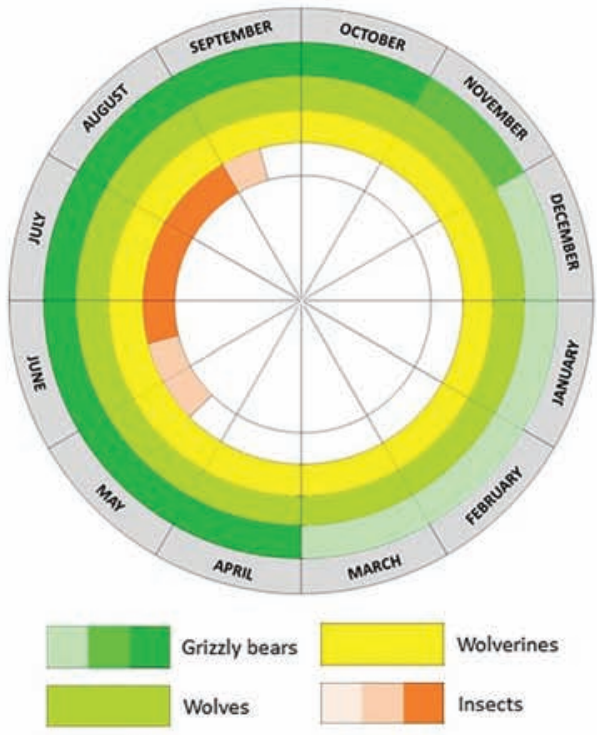

FIG. 3. Yearly calendars summarizing interviews and validation sessions showing the timing of key life events (a) and of factors that negatively affect muskoxen within their physical (b) and biological (c) environments. The four-color gradient represents the percentage of groups that had indicated the month during the interviews and was built as follows: white $=0 \%$, light color $=0.01 \%$ to $\leq 33.33 \%$, mid-tone color $=33.34 \%$ to $\leq 66.67 \%$, and dark color $=66.68 \%$ to $\leq 100 \%$. If all groups indicated the same information, then only one color instead of three was used (i.e., corresponding to $100 \%$ ).

"yeah, it would be harder for them to dig, but that's a huge animal" and "they are big strong animals, and they know how to manage."

Similarly, several participants mentioned that deep snow made it difficult for muskoxen to access their food. During validation sessions, one participant added that deep snow may render them more vulnerable to predators by slowing them down when running away because of their short legs. Conversely, some participants considered that it would not affect them because muskoxen typically remain in windblown areas with little snow (i.e., on top of hills).

While heavy snowfalls still occur, most participants observed a gradual general decrease in the amount of snow since the 1960s (Elders), and even more so since the early 2000s (Elders and non-Elders). The amount of snow is highly variable among years and also depends on the area, with some locations more affected than others. All participants concurred that reduced snowfall makes it easier for muskoxen to access food. One interviewee mentioned: "They have a better chance winter time around here nowadays. There's not as much snow as there used to be, so they don't have to dig as far down to get to their food."

All participants emphasized high variations in rainfall (i.e., "it's up and down all the time") among years, with the occurrence of very rainy years. Some mentioned observing a general decrease in rain over the past $10-15$ years, while others described an increase or no change. According to most participants, only freezing rain has negative impacts on muskoxen. Otherwise, rain was considered positive, relieving them from the heat and "making the land grow," consequently allowing the animals to get fat. One interviewee pointed out: "It [the rain] helps them lots. It keeps the bugs down, keeps them [muskoxen] cool. They can have water anywhere, they don't always have to go find water at a river, there's puddles all over the place, they can keep hydrated. It keeps better growing for the plants, so they got more food, it's easier to get."

Many participants described the "land drying up" since roughly the 1990s, with lakes, creeks, and ponds drying out, and river levels going down. Victoria Island was more significantly affected by this phenomenon than was the mainland. One interviewee observed in regards to Victoria Island: "There are places where you go and it's like walking on gravel, it's so dry." Factors contributing to the "land drying up" include a general decrease in snow, a marked increase in permafrost thaw, longer summers and higher temperatures, as well as a low amount of rain; once again, there are substantial seasonal and annual variations. The impacts of the "land drying up" on muskoxen are mostly through the quality and abundance of the vegetation (see Biological Environment), but they are also sometimes forced to move away. For example, over the past decade, multiple interviewees observed migrations of large muskox herds in early spring before the sea ice starts melting from Victoria Island to the mainland. They connected these migrations to the vegetation on the mainland, which is better both in quantity and quality compared to Victoria Island.

A few participants thought that a large amount of slush during snowmelt causes muskoxen to slow down or get stuck and to sometimes even die of exhaustion, but this happens only on rare occasions and mostly to weaker and older animals. Two validation groups also linked muddy terrain to areas with permafrost thawing. Such terrain is difficult for muskoxen to maneuver and may cause them to get stuck. One participant shared his observation of a likely sick muskox who got stuck in the mud and ended up dying. 
One validation group added that global warming has caused the permafrost to thaw and release methane into the atmosphere. Participants were concerned that this might negatively affect the lungs of muskoxen.

Biological Environment: Aspects of the biological environment, such as predators and vegetation, were considered to have both positive and negative impacts on muskoxen, while others, including low caribou abundance, insect harassment, and lungworms were thought to have a negative effect (Fig. 2). The timing of predator and insect activity is illustrated in Fig. 3c, but the timing of the other negative factors, such as poor vegetation and lungworms, was not discussed in depth.

Predators, including wolverines, wolves, and grizzly bears, had both positive and negative impacts on muskoxen. Participants unanimously observed no change in the abundance of wolverines over the years, but noted an increase in the abundance of both wolves and grizzly bears since the 1980s-90s, which was more evident on Victoria Island than on the mainland. Interviewees also observed an increase in the number of cubs per grizzly bear sow over the past decades. Predation on weak and diseased muskoxen was considered positive as it would limit the spread of diseases throughout the herd. However, mortality caused by predation was significant, as was the stress caused by predators chasing and scattering the animals and herds. Participants indicated that wolverines, wolves, and grizzly bears are capable of killing any muskox, even very healthy ones, but they generally favor "easier" prey such as lateterm pregnant females, and young, old, injured, or diseased muskoxen that fall behind when the herd is chased, as well as lone animals.

Wolverines and wolves were consistently observed yearround, whereas grizzly bear activity was restricted because of annual hibernation (Fig. 3c). Grizzly bears are mainly active between April and October with most hibernating by November, excluding a few who are not fat enough and hibernate later. One participant told the story of a skinny bear that killed two dogs at the edge of Kugluktuk in November and another mentioned: "A big bear who doesn't have enough to eat yet, he still needs to fatten up some, so he'd wander around a little bit longer than everybody else." While some odd grizzly bear sightings were reported between December and March, these would be very rare occurrences, probably corresponding to very hungry bears. Finally, one participant added that: "Highest activity would be April-May and September-October. When they first come out, they come out almost all at the same time, few weeks apart, so you're gonna have a big flood, and they're all starving right? And then just before they're gonna go back to sleep, they're going to pack on as much pounds as they can, and that's all of them."

One interview group suggested that changes in plant species may have contributed to the muskox declines on Victoria Island: "other plants are growing more and then they're just not right for the muskox diet ... The vegetation there [Victoria Island], it's probably from that, they might be starving and getting sick from other plants that their bodies are not used to." A few participants described changes in plant species on the mainland and expressed their worry that some of the newly established plants may be invasive and take over native species in the future. However, most participants in validation sessions did not express an opinion (i.e., this is not something they have been paying attention to) or thought muskoxen would only eat plants that they like: "If muskoxen don't like the other plants, they won't eat them, they'll only eat what they like to eat." People would, however, "just have to wait and see" what impacts changing vegetation will have on muskoxen.

The "land drying up" was raised multiple times. Participants voiced that this negatively impacts plant growth and, consequently, negatively affects muskoxen through decreased food availability, abundance, and quality. However, a few participants thought that the impact on muskoxen would be limited as they would be able to find food elsewhere, in less affected areas such as along riverbanks or around wetlands. Several participants mentioned that Victoria Island, described by them as having poorer vegetation than the mainland, was more significantly impacted by the "land drying up." Conversely, longer summers could lead to longer periods of high vegetation growth, depending in part on the amount of rainfall, which increases both the abundance and quality of the vegetation. This high vegetation growth positively affects muskoxen by giving them "a lot more to eat for a lot longer" and "they would get fatter because they're grazing a lot more." The relative importance of opposing impacts of climate warming (i.e., the "land drying up" versus a longer growing season and better vegetation quality and quantity) varies depending on the year, area, and weather conditions (amount of rain, temperature, etc.).

Declines in caribou abundance were thought to have negative impacts on muskoxen, which are harvested more intensively to compensate for caribou scarcity. However, one interviewee commented that muskoxen would not be significantly affected because their harvesting is regulated via a tag system administered through the Nunavut Government.

Lungworm infections were thought to reduce lung capacity and endurance of muskoxen, rendering them more vulnerable to predators and making it more difficult for them to search for and find food.

Insects in general, and mosquitos in particular, were discussed by all participants. The diversity of insect species has increased since the $1980 \mathrm{~s}-90$ s, possibly due to a combination of climate warming (i.e., increasing temperatures and longer summers) and airplanes and sea lifts bringing up new species. One participant had worked with a biologist during the previous summer and trapped hundreds of different fly and mosquito species, many of which were previously unknown in the area. While most interviewees described no change in the abundance of insects but strong yearly variations, a couple of participants thought there had been an increase over the past decades. 
Several people also mentioned that the duration of insect activity was getting longer.

A few participants had difficulties expressing an opinion regarding the effect of insects on muskoxen as they rarely observed muskoxen during the summer. However, some mentioned that muskoxen are less harassed by insects and are less sensitive than caribou because of their thick skin and long fur that protect them: "they don't seem too bothered by them [insects] because of their long hair" and "I don't think they do anything to the muskox. Cause you got, you know, a good 6 to 8 inches of hair, and underneath that you got a good thick wool, that thing might overheat just trying to get in there! Probably knows it too!" Muskoxen are affected on their face and legs where the hair is shorter, and younger animals might be particularly sensitive because of their thinner skin and hair. Muskoxen were rarely seen running from insects, even when these are highly abundant, but sometimes muskoxen would stay in rivers to avoid insect harassment, and summer days with no wind exacerbate harassment. Insect harassment can cause moderate restlessness with animals moving more and eating less. One participant concluded that the herd would generally not be affected and remain calm, but that the "odd" muskox may be seen running around "sick and tired of bugs buzzing in [its] ear."

Human/Muskox Relationships: A breakdown in Inuit knowledge transmission, non-renewable resource exploration and development, hunting, and other anthropogenic disturbance were identified to negatively impact muskoxen; conversely, hunting regulations were identified to have a positive effect (Fig. 2).

Participants thought that the lack of knowledge transmission with respect to hunting and butchering led to people sometimes "not knowing what they're doing" and engaging in improper harvesting practices, which had a negative impact on muskoxen. These practices include (1) not approaching muskoxen properly and chasing them more, causing increased disturbance and stress, (2) unfamiliarity in identifying healthy muskoxen, with abnormalities in the organs and meat, and in preparing meat and organs to ensure food safety; these knowledge gaps may result in meat wastage, and (3) not having appropriate training in sighting-in firearms and targeting the right animal for harvest. These improper hunting practices, although infrequent, may occur in both youth and adults. Interviewees suggested that youth/Elders and inexperienced/experienced harvester programs that promote the sharing of knowledge and cultural traditions among generations could address this breakdown in knowledge transmission.

Some participants were worried about air, ground, and water pollution, while others thought that pollution was limited in the Arctic, and still others had no particular opinion on the matter. Mining activities were of particular concern for several participants. The chemicals released in the environment, as well as windborne dusts and fumes, were thought to degrade vegetation and to contaminate lakes and other water sources, with a consequent decrease in water quality. Participants mentioned that all wildlife species would be affected by pollution from mines although they were unsure of the specific impacts. One participant who used to work in the mines described that "sometimes, there would be a huge yellow cloud and the wind carries it, I don't know how far, but I believe it affects most animals," and another interviewee mentioned that "anything with mines will affect the wildlife one way or another." A few participants suggested that because mining activities were done on a small scale, the adverse effects would be very limited. Those who had observed muskoxen around the mines reported animals as generally scarce, but also described a recent increase in their abundance near the mines. Additionally, participants specified that the pollutants released would be carried over long distances and affect muskoxen even if they were located farther away.

Several participants considered hunting as causing disturbance to muskoxen. Sport hunting in particular was considered to cause the loss of "prime" bulls whose genes would potentially produce strong and healthy progeny: "They always take the champ. And you kind of want the champ to be the one to pass on the genes, strong, you know good line." While most participants agreed with this effect, a few had a more reserved opinion on the matter, as they said (1) there would always be other males to take over, especially if the population is abundant, (2) the males with the biggest bosses and horns targeted by trophy hunters may actually be quite old, not reproducing anymore and not necessarily the healthiest, and (3) the number of males harvested for trophy would generally be low, and their loss would consequently have a limited impact on the population.

Several participants thought that subsistence and community hunting caused the loss of young animals and possibly pregnant females. Most interviewees agreed with this impact and one suggested the implementation of seasonal hunting regulations that would ban people from harvesting female muskoxen around calving time. However, a few had reservations and thought that when the population is abundant and healthy, this loss would not have a significant effect especially with the number of muskoxen hunted regulated through the tag system. One participant mentioned that it would even have a positive effect by keeping the population at a reasonable number and preventing overgrazing of the land. Additionally, some Elders consider muskox fetuses as a delicacy, and thus there would be limited wastage if pregnant females were harvested.

Participants of the first validation session added helicopter activity and the resulting noise pollution to the factors negatively affecting muskoxen; most interviewees subsequently agreed with this addition. Helicopters were described as very noisy, consequently disturbing and scaring muskoxen, and causing them to run away. Conversely, a few participants did not think this impact to be significant; one person mentioned: "I've been in a helicopter and flown by them. They will just run a little bit, and then they'll stop and resume what they were doing, 
feeding and what not." More generally, interviewees thought that airplanes flying low over the land would affect muskoxen, but these were described as rare occurrences.

Seasonal patterns of disturbance were further explored during validation sessions. Snowmobile activity generally begins between October and December and lasts until May or June, depending on the timing of freeze-up and breakup, respectively. Airplanes operate year-round, while helicopters, which are mainly linked to exploration and mining activities, are observed primarily between April and September. All-terrain vehicles (ATVs) are used only during the summer months, and most interviewees said that they would not cause major disturbance to muskoxen as people can't travel very far with them. Moreover, muskoxen are generally scarce in the areas accessible by ATVs. In contrast, one participant indicated that when he comes across muskoxen on Victoria Island, where it is easier to travel by ATV because the land is flatter: "Unless we're trying to get close to them, they don't even really bother with us. They'll stop and just watch us go by, and carry on." Participants specified that anthropogenic disturbance is lowest between June and September, as airplanes, helicopters, and ATVs generally cause lower stress than do snowmobiles, whereas it is highest during periods of high hunting activity, in November-December and March-April, when a lot of people are out on the land with snowmobiles.

All participants agreed that measures favoring predator management such as increased hunting incentives and reduced regulations (e.g., trapping for predators allowed all year round and no tag system) were positive for muskoxen as they reduced predator abundance and consequently predation. Similarly, all participants concurred that the tag system to harvest muskoxen was positive as it controlled and kept at a reasonable level the number of muskoxen hunted. However, some interviewees suggested that when the population is abundant, this regulation could be lifted for subsistence and community hunting.

\section{IK Perspective of Published Stress Results}

We asked the participants to discuss the results from a previously published study on locally harvested wild muskoxen that showed differences in hair cortisol levels across sex, seasons, and years (Di Francesco et al., 2017). Throughout the discussions, hair cortisol levels were colloquially referred to as "stress levels."

Sex Differences: Di Francesco et al. (2017) reported higher hair cortisol levels in males than in females. None of the seven groups were surprised by this finding and all groups attributed this in a large part to reproduction (i.e., rut and mating). In particular, rut was considered a time of high stress with some bulls getting killed during fights, and others dying from exhaustion and starvation afterwards, as they would have been eating less and used up all their energy and fat stores by the end of the rut. Additionally, bulls were thought to be weaker and more vulnerable to predators after the rut. While all participants agreed with the latter observation, one interviewee thought that reproduction was "normal" and that stress during that period would mainly be due to injuries. During a validation session, one person not previously interviewed mentioned being surprised by the sex differences measured and figured that female muskoxen may be stressed by their role of raising the young.

Three groups mentioned that males had the important role of protecting and taking care of the herd. They represent the "first line of defense" against predators and other threats and have to find food for the rest of the herd: "Once the male has established the herd, then he'll take care of them and they don't have to worry about finding food, he'll find them food." The role of protection was all the more emphasized with the increase in the abundance of wolves and grizzly bears observed and would not be restricted to the dominant male but would also involve the younger males. However, one participant thought that all adult muskoxen and not necessarily the males only contribute to protecting and taking care of the herd. Interviewees also thought that if a herd is split up (i.e., by harvesters or predators), it would be particularly stressful for the male as he would lose some of the females he was responsible to protect.

Several participants identified sport hunting as a stressor of bulls because sport hunters generally try to find bachelor herds with only bulls, although it was also highlighted that the male groups are not the only ones disturbed and females would not be aware that they're not the target. One interviewee illustrated this viewpoint: "It doesn't matter how many males or females you got in a herd, as soon as they see danger or sense danger, everybody comes together, in a circle. It could be all males, it could be all females, it doesn't matter ... No matter what, no matter who's hunting, sports hunters or me, we're all going to have the same stress on that animal. Cause they don't know what you're coming for, you come to kill us all, or are you just here for me? They got no concept of that ... It's all a predator no matter what it is, everybody's in danger, at all times, so it's the same stress level."

Some interviewees also thought that male muskoxen were more sensitive to the heat than females because they move around more to protect and find food for the herd. However, while most participants agreed with this observation, others did not express an opinion or disagreed as "they move around more, but slowly." One participant added that "the higher heat would affect the male more cause he's all worked up too [by sexual arousal during the rut]."

Factors more specific to younger males were also brought up. Young males get chased away from the herd more frequently and consequently have a harder time finding a good place to feed. These occurrences are generally only during the rut: "When you get into the herd, there's never only one male, there's lots, and there's young ones, and there's big ones. They don't really get kicked out per se, only rutting time." Young males also have to search more for food to respond to their higher nutritional needs due to 
their rapid growth compared to females. Finally, they tend to fight more frequently than older bulls.

Seasonal Differences: We then asked participants to discuss the previous findings of lower hair stress levels in muskoxen in the summer than in the fall and winter (Di Francesco et al., 2017). One of the seven groups was surprised by this finding, given the multiple summer stressors, which included heat stress, insect harassment, and predators. Helicopter activity was unanimously added to the list during the validation sessions, and airplanes and ATVs, low air quality (from pollution, forest fire smoke, etc.), poor vegetation (which would depend highly on the year), and muddy terrain were also added by some of the validation groups. Specific to the fall, all participants identified reproduction as the main stressor (i.e., rut and mating, including injuries from fighting, which may take a while to heal).

Participants suggested various explanations for the higher stress levels observed during fall and winter. These included (1) lower food availability, quality, and accessibility (4 groups), as muskoxen have to break through the snow or dig to access their food, and in some places the snow may get very hard because of freezing rain events or temperature variations, (2) higher harvesting pressure and human disturbance (3 groups) as these are the main hunting seasons and access to the land is easy using snowmobiles (i.e., "It's mostly in the winter time cause we have access, we can travel by snowmobile to them. We can go anywhere."), and (3) higher pressure from predators (1 group) as they have access to a lower diversity of prey than in the summer.

Yearly Variations: Discussions around yearly variations (i.e., increase in stress levels from 2013 to 2015 and no significant difference between 2015 and 2016) were more challenging as participants had difficulties recalling events that occurred during specific years. Interviewees did, however, discuss the various factors that could contribute to interannual differences in stress levels. These factors included variations in competition between muskoxen, predator numbers, weather conditions, and human disturbance. Some interviewees indicated that competition between muskoxen mainly takes place during the rut and increases with the number of males in a herd as well as with the general abundance of muskoxen: "because then a big male wants to keep his harem, he's gonna fight a lot more than he would if there was less [male muskoxen]." During the validation sessions, all participants unanimously agreed with these factors, and one group added the importance of annual variability in air quality, which would be impacted, for example, by mining activities, forest fire smoke, or volcanic eruptions.

\section{DISCUSSION}

\section{Characteristics of a Healthy Muskox}

A primary goal of this research was to document IK on muskox health to facilitate a more holistic understanding.
Recent work has focused on updating and broadening the definition of wildlife health, and it now encompasses not just the absence of disease, but also the concepts of vulnerability, resilience, and population sustainability (Hanisch et al., 2012; Stephen, 2014). However, examples of the inclusion of IK holders in developing this definition are scarce. As an illustration, two recent studies used the Delphi method, which aims at soliciting and subsequently summarizing the knowledge of a group of experts to establish a definition of wildlife and polar bear health, respectively (Hanisch et al., 2012; Patyk et al., 2015). However, there was no explicit connection to Indigenous worldviews and all experts who participated in these studies were identified by affiliation to government agencies, research or academic institutions, or nonprofit organizations (Hanisch et al., 2012; Patyk et al., 2015).

Indigenous peoples' concept of health is relatively well established in human medicine. Rather than focusing on the individual, it generally includes the health of the entire community and its surrounding ecosystem, while incorporating a multitude of dimensions (i.e., social, physical, psychological, spiritual, and ecological) (Stephens et al., 2005; Janska, 2008). This holistic view of health extended to wildlife was highlighted in our study by the multiplicity and wide diversity of the characteristics brought up by the participants when we asked them to identify what enables them to establish if a muskox is healthy. Indeed, these encompassed external and internal elements, physical and behavioral traits, and individual and herd features. Additionally, some of these characteristics were intrinsically broad, such as the muskox's behavior, which comprises a variety of aspects including their attitudes, reactions, movements, and capacity to defend themselves. Stephen (2014) emphasizes that the health of wildlife species results from the cumulative effect of multiple biological, social, and environmental factors that act on individuals and populations and affect their capacity to cope with change. This integrated definition resonates strongly with and could be further informed by Indigenous ways of knowing, as IK holders simultaneously examine animals and their complex and changing environment, including its human dimensions (Kutz and Tomaselli, 2019).

\section{Positive and Negative Factors Affecting Muskoxen}

The holistic perspectives strongly expressed by what characterizes a healthy muskox were continued throughout subsequent discussions on the factors that affect muskoxen. The TIK documented in this study again illustrated a One Health perspective relevant to this question, with the various factors influencing muskoxen discussed simultaneously and their multiple interconnections emphasized. An overarching theme that emerged from the interviews was that muskoxen are living in a changing world (Fig. 2) and within it, they are highly influenced by a multitude of interrelated elements across a variety of spatial and temporal scales, including weather and climatic 
factors, animals and plants sharing their ecosystem, as well as the human dimensions of the world they live in. The Intergovernmental Panel on Climate Change (IPCC) clearly documents changes in the global climate (IPCC, 2014); the impacts of those changes on muskoxen, and more broadly, on the physical, biological, and cultural environment in the Arctic were articulated in rich detail by the participants.

Participants' observations and perceptions regarding the factors that affect muskoxen often concurred with and expanded on the current scientific understanding of Arctic ecology, but also generated novel insights and new questions. While excessive and prolonged heat was considered an important factor having a direct influence on muskox health and well-being, muskoxen were also able to behaviorally mitigate this stressor by reducing their activity level and remaining in windier areas. The scientific literature on the effects of heat on muskoxen is sparse, with only a single study linking heat to an outbreak of fatal pneumonia in the muskox population of Dovrefjell in Norway (Ytrehus et al., 2008, 2015). The effects of high heat on muskox behavior and physiology otherwise remaining poorly understood (Kutz et al., 2017). Further research bringing together both IK and SK is needed to investigate the interactions of warming temperatures with other possible stressors and the resulting cumulative effects of all stressors on muskoxen. Some of the hypotheses generated in this study could be explored through targeted SK studies, as has previously been done for brucellosis in muskoxen (Tomaselli et al., 2018b, 2019).

Increased insect diversity, changes in insect abundance, and longer periods of insect activity were reported by the participants. Similar findings have been described through other IK studies in the Canadian Arctic (Huntington and Fox, 2005; Prno et al., 2011). Of particular note was that participants had observed the effects of insects on muskoxen. While the impacts of insect harassment are well documented for caribou (e.g., Witter et al., 2012; Raponi et al., 2018), only one study has investigated these in muskoxen. Jingfors (1982) found evidence that muskoxen increased the proportion of time spent walking and standing, while they decreased the proportion of time spent feeding when insect harassment level was high. Participants, therefore, provided valuable descriptions and unique insights regarding the negative effects of insect harassment on muskoxen, which, based on their accounts, are probably limited but still relevant.

Participants described increased wolf and grizzly bear abundance, which was more evident on Victoria Island than on the mainland. Similar observations, and particularly the northward range expansion of grizzly bears into the Canadian Arctic Archipelago, have been reported in other SK and IK studies (SARC, 2013, 2017; ECCC, 2018; Tomaselli et al., 2018b). While participants emphasized the negative effect of predators through the disturbance of muskoxen and direct mortality, particularly of the more vulnerable individuals, they also highlighted that predation limits the spread of diseases throughout the herd. This beneficial role of predators in the control of infectious diseases has been discussed in various scientific studies (Packer et al., 2003; Hall et al., 2005; Wild et al., 2011) and was previously suggested by Kugluktuk IK holders: "Wolves keep the caribou in good health. If there would be no wolves, there would be lots of sick caribou" (Dumond, 2007:17).

Participants indicated a general decrease in the amount of snow that had a positive effect on muskoxen through easier food accessibility and availability, but also contributed to the land getting dryer, particularly on Victoria Island. Enhanced drying of local lakes and rivers and decreased water levels have been documented through other IK studies in Nunavut and the Yukon (Huntington and Fox, 2005; Wrona et al., 2005). This phenomenon of the "land drying up" has, among other negative impacts, forced muskoxen to move away, and multiple participants recounted muskox migrations from Victoria Island to the mainland in early spring. These accounts are further supported by the findings of a recent study analyzing muskox gut microbiome and microsatellite data, which demonstrated that a few of the muskoxen sampled on the mainland clustered with those from Victoria Island (Bird et al., 2019). Participants also reported the negative effects of high snow hardness and snow depth on muskoxen through reduced food availability and accessibility. The frequency of rain-on-snow events is predicted to increase in the Arctic (Hansen et al., 2011; Langlois et al., 2017), so the impacts of these events on muskoxen will likely become more severe in the future.

The complexities of the interactions among altered precipitation (i.e., both rain and snow), warming temperatures, thawing permafrost, and other consequences of climate change, as well as the diversity of their effects on the land, vegetation growth, and other animals (i.e., insects and predators) were highlighted throughout the participants' narratives as they considered all of these factors simultaneously and comprehensively. As current climate change trends are predicted to continue (IPCC, 2014), it is likely that the direct or indirect impacts of these various factors on muskoxen will intensify in the future.

Among anthropogenic factors, participants mentioned a negative but probably limited impact of sport hunting on muskoxen through the loss of prime bulls with valuable trophy phenotypic characteristics (i.e., big boss and horns). This impact recalls the findings of scientific studies in bighorn sheep (Ovis canadensis) and mouflon (Ovis gmelini musimon), where unlimited sport hunting resulted in the decline over time in those populations of some of the heritable traits for which trophy-harvested rams were selected, such as body and horn size (Coltman et al., 2003; Garel et al., 2007). Other impacts of human disturbance (e.g., the use of various vehicles and hunting activities) were further exacerbated by the breakdown of Inuit knowledge transmission on proper hunting practices. Observations that approaching muskoxen improperly generates higher stress echo the findings from a review study of ungulate 
flight responses to human disturbance, which found that ungulates flee greater distances when they are approached in a more threatening manner by humans (i.e., directly or rapidly) (Stankowich, 2008). All of the negative impacts of human disturbance on muskoxen identified by the participants are also likely to intensify in the future with increasing anthropogenic activities in the Arctic (Post et al., 2013; AMAP, 2017).

The content of IK is inextricably linked to its spatial context (Wilson, 2008; Kovach, 2009; Berkes, 2018). This linkage was exemplified in this study by the way participants detailed the spatial context of their knowledge in addition to muskox-specific content. For instance, they described different phenomena depending on their areas of observation, which generally corresponded to where they had lived and travelled. This connection between context and content was further highlighted by some of the specific differences between Victoria Island and the mainland around Kugluktuk regarding environmental changes, their severity, and their impacts on muskoxen. Variations in the observations and interpretations of participants from the same community reflect the context and relationality that led to the creation of the knowledge (Wilson, 2008; Kovach, 2009; Maxwell and Mittapalli, 2010). These variations also prompt us to pay close attention to IK geographic areas of observation and to consider individualspecific nuances in IK when trying to abstract to the community level (Armitage and Kilburn, 2015; MartinezLevasseur et al., 2017).

Because of logistical and financial constraints, only Kugluktuk IK holders were included in this study. However, this research would have greatly benefitted from involving all the Canadian northern communities participating in the muskox health monitoring program to capture a broader range of reflections and observations and possibly identify other factors that may have been missed because they were not occurring around Kugluktuk. Since muskoxen are typically non-migratory animals (Gunn and Adamczewski, 2003), the content-context link suggests that Kugluktukspecific observations would well represent the muskoxen around Kugluktuk for the seasons that harvesters interact with the animals. However, participants in this study indicated that muskoxen were emigrating from Victoria Island to the mainland, adding another component that requires consideration. Hanke et al. (2021) emphasize the importance of including different community perspectives to understand the Dolphin and Union caribou herd (Rangifer tarandus groenlandicus $x$ pearyi). A multi-community study would be similarly useful for muskoxen to further understand their health, ecology, and behavior, and their relationships with people across different landscapes.

Some of the participants' accounts conflicted (e.g., observations regarding changes in the amount of rain over the past decades and speculations on the fur of muskoxen rendering them sensitive to the heat versus keeping them cool). Such inconsistencies and contradictions may be linked to differences in participants' experiences or to variations in the spatial extent and time frames of their observations (i.e., knowledge increases with age and the amount of time spent on the land, but some older Elders may also have decreased their harvesting activities, thus lacking more recent experience on the land). The contradictions regarding predators (i.e., a decreased amount of snow makes it easier for predators to go after muskoxen versus deep snow renders them more vulnerable to predators) may be due to the inclusion of "muskox experts," who may not have extensive knowledge on predators. However, it is also important to note that the search for consensus is a preoccupation of SK and not necessarily that of IK holders, who may value the diversity of interpretations and opinions (Armitage and Kilburn, 2015). This idea is well illustrated in a study involving Alaskan Yupik: "There is no privileged point of view: the individuality and multiplicity of human experience and perception make definitively collective statements about the world impossible.... It is preferable to present multiple accounts rather than to try to reduce them to common elements." (Morrow, 1990:153). Additionally, the majority support for a particular observation or theory does not necessarily prove its validity. In this study, we consequently chose not to eliminate contradictions, but rather document the diversity of observations and theories expressed by the participants.

The inclusion only of participants who were specifically knowledgeable about muskoxen and the relatively narrow aim of this study allowed us to achieve high information power (Malterud et al., 2016). While some of the information documented during our interviews appears to conflict with the SK literature (e.g., "they don't have to worry, he'll [the bull] find them food") in which feeding movements of the herd are thought to be influenced by any of the herd members (Gray, 1987), this discrepancy may reflect differences in participants' experiences as well as suggest important ecological nuances that have not been recognized through scientific study alone. The seasonality of land use, and particularly that muskox harvesting during the summer was uncommon, is reflected in what the participants know about muskoxen, and the information documented for that season must be interpreted in that light. Additionally, while the small groups were arranged by age in order to minimize any power dynamics, the setting still may have limited the expression of shy and less outspoken individuals, especially if their opinions and observations differed from that of the majority.

\section{IK Perspective of Published Stress Results}

In the last part of this study, we discussed with TIK holders data on the sex, seasonal, and yearly variations in hair cortisol levels of wild muskoxen. This work of collaboratively interpreting physiological stress results with IK holders seems almost common sense, but to our knowledge this process is unique in the field of wildlife endocrinology research. 
Kutz and Tomaselli (2019) highlight that the process of combining and contrasting findings from different knowledge systems provides greater insights as they can, among other things, compensate for each other's uncertainties. Participants in this study identified additional explanations and hypotheses for the patterns observed in the Di Francesco et al. (2017) study and supported and complemented previously recognized stressors. They also elaborated, through their holistic view and close intimacy with their environment, on the complex interconnections among the various factors mentioned. For example, regarding seasonal variations, heat extremes and insect harassment were identified both through the scientific literature review and by the participants as possible summer stressors. Interviewees further were able to describe the severity of the effects that heat and insects have on muskoxen, the strategies muskoxen use to cope with them, and their implications in a future of climate warming. Additionally, poor air quality from pollution or smoke, muddy terrain, and anthropogenic disturbance from helicopter, airplanes or ATV activity were identified by participants but not considered in the original interpretation of the hair cortisol results. TIK also was able to provide new information on the timing and severity of fall and winter stressors and their interconnections. The higher pressure from predators was a new factor added through TIK.

Participants identified several stressors in summer and were surprised that these were not reflected in the summer hair stress levels. However, this may be a limitation of the hair growth biology and the scientific method used. There is a delay between when a potential stress-induced increase in cortisol is incorporated into the hair in the follicle and when that part of the hair surfaces above the skin. Consequently, late summer stressors associated with rut may not be detected in the hair until it surfaces several weeks later (i.e., in the fall). Findings from the interviews allowed us to gain a broader understanding of sex specific stressors and the functions, particularities, and behavioral characteristics of male muskoxen that may lead them to having higher stress levels. Additionally, the fact that none of the participants were surprised by these sex differences increases confidence in the hair cortisol results in $\mathrm{Di}$ Francesco et al., (2017), which were based on limited and unbalanced sample sizes. Finally, for the factors possibly contributing to the variations in stress levels among years, findings from the interviews supported and expanded on the discussion in Di Francesco et al. (2017).

Our study is an example of how IK can inform quantitative species status assessments and conservation measures as suggested by Peacock et al. (2020). The IK we documented identified relevant indicators of muskox health and measurable variables that could be used to inform these indicators. Potential indicators, which are analogous to determinants of health and emanated from the participants' accounts, include multiple extrinsic factors such as indices of helicopter traffic and snowmobile activity, measures of plant abundance and quality, indices of insect harassment taking into account both the abundance of insects and the duration of their activity, and measures of air quality, for example. Future work will focus on developing such indicators and their measurable variables, using both SK and IK, so they can be used to further understand individual and population-level hair cortisol concentrations.

Our aim through this research is to strengthen the integration of IK and SK to gain a better understanding of the stressors that affect muskoxen. Danielsen et al. (2009:34) proposed a five-category classification of natural resource monitoring programs based on their degree of community involvement and ranging from "externally driven and professionally executed," without any participation of local stakeholders, to "autonomous local monitoring," without any direct involvement of external agencies. The hunter-based muskox health monitoring program, from which the muskox hair samples were obtained, originally fit in Danielsen et al.'s third category of "collaborative monitoring with external data interpretation, which involves local people in data collection and management-oriented decision making, but the design of the scheme and the data analysis are undertaken by external scientists" (Danielsen et al., 2009:33). Indeed, the concerns around muskox health were raised by the communities, and the sampling kits were designed in collaboration with local harvesters to allow for the collection of a standardized set of samples and were adapted to the extreme field conditions encountered in the Arctic (Tomaselli, 2018). However, all sample and data analyses were conducted by researchers with results regularly brought back to the communities for further discussions. Our current study, in addition to the training of an Inuk resident (T. Milton) of the community in sample analyses, moves this program closer to Danielsen et al.'s fourth category corresponding to "collaborative monitoring with local data interpretation, which involves local stakeholders in data collection, interpretation or analysis, and management decision making, although external scientists may provide advice and training" (Danielsen et al., 2009:33-34).

To ethically and successfully bring together SK and IK, IK holders should be engaged across all stages of the research from study design to data interpretation and validation so that the combination between the two knowledge systems can reach its full potential (Ban et al., 2018; Bélisle et al., 2018). Furthermore, the Nunavut Land Claims Agreement Act led to the establishment of the Nunavut Wildlife Management Board, a co-management board mandated to equitably consider all available SK and IK in their wildlife management recommendations (INAC, 1993). Transitioning northern research to categories four and five on Danielsen et al.'s (2009) hierarchy is congruent with calls from the Nunavut Research Institute and Inuit Tapiriit Kanatami (ITK and NRI, 2006; ITK, 2018). It also creates the conditions for fruitful and durable collaborations and, in the case of this program, positions it to more effectively achieve the goal of promoting the health and sustainability of muskoxen for the communities that depend on them and strengthens the co-management process. 
Our study has addressed three points integral to transitioning into a more collaborative and well-integrated research program: (1) documenting TIK to determine the characteristics of a healthy muskox and identify the stressors affecting them, (2) understanding, from an IK perspective, the results from a related SK study, and (3) partnering with an Inuk resident of the community in the interviews and data analyses. We have done this by providing a platform for the participants to speak about muskoxen, including many harvesters who are actively involved in the hunter-based sampling program. Also, our use of small group interviews and validation sessions acted as another opportunity for exchange and co-production of knowledge among the various parties participating in the project. For example, through the process, J. Di Francesco responded to interviewees' questions on sample analysis methods and other study findings, while TIK holders shared their detailed observations, including possible explanations and hypotheses, to inform the interpretation of results. Finally, T. Milton, who co-coordinates the hunterbased sampling program in Kugluktuk and does the initial sample analyses, also participated in the interviews and data analyses.

\section{CONCLUSION}

In this study, we documented TIK to identify and gain a better understanding of the stressors affecting muskoxen. The holistic One Health perspective expressed by the TIK holders allowed for a broader and deeper comprehension of the stressors affecting muskoxen, their complex interconnections, and how these contribute to the sex, seasonal, and annual patterns observed in muskox stress levels. Additionally, this study illustrated the importance of bringing together SK and IK, and how the Inuit perspective reflected a One Health approach in all sections of the interviews. This study also represented a meaningful advancement in the process of transitioning the muskox health monitoring program to the "collaborative monitoring with local data interpretation" category by actively involving communities in data interpretation and not just data collection. More broadly, this work showed that many studies, particularly in the complex field of wildlife endocrinology research, could benefit from involving IK holders in both hypothesis generation and data interpretation to gain a more holistic understanding of the patterns measured.

\section{ACKNOWLEDGEMENTS}

We thank all of the Kugluktuk Angoniatit Association board members from 2018 to 2020, including Larry Adjun, Kevin Klengenberg, Bobby Anavilok, Colin Adjun, Jayko Palongayak, Margo Nivingalok, Peter Taktogon, Stanley Carpenter, Sammy Angnaluak, and Bessie Sitatak for their continued support. We also thank Amanda Dumond, Russell Akeeagok, and Allen Niptanatiak for their invaluable guidance and help throughout this study, as well as the Hamlet of Kugluktuk and Kugluktuk High School for their assistance. Finally, we acknowledge the late Jorgen Bolt, who generously shared with us his tremendous knowledge of muskoxen and the land and passion for wildlife.

J. Di Francesco was funded by the Morris Animal Foundation Fellowship Training Grant D18ZO-407 and a University of Calgary Faculty of Graduate Studies Doctoral Scholarship. A. Hanke was funded by the Natural Sciences and Engineering Research Council Canada (NSERC) Graduate Scholarship Master's, the Northern Scientific Training Program, Mitacs Accelerate IT14527, the Association of Canadian Universities for Northern Studies, and Environment and Climate Change Canada Project GCXE20C347. This work was supported by Canada North Outfitting, Polar Knowledge Canada Grant NST-17180015, NSERC Discovery Grant RGPIN/04171-2014, an NSERC Northern Supplement - RGPNS/316244-2014, ArcticNet, and Irving Maritime Shipbuilding.

\section{REFERENCES}

AMAP (Arctic Monitoring and Assessment Programme). 2017. Snow, water, ice and permafrost in the Arctic (SWIPA) 2017. Oslo, Norway: AMAP.

https://www.amap.no/documents/doc/snow-water-ice-andpermafrost-in-the-arctic-swipa-2017/1610

Armitage, P., and Kilburn, S. 2015. Conduct of traditional knowledge research - A reference guide. Whitehorse, Yukon: Wildlife Management Advisory Council North Slope.

https://wmacns.ca/resources/conduct-traditional-knowledgeresearch-reference-guide/

Baker, S., and Constant, N.L. 2020. Epistemic justice and the integration of local ecological knowledge for marine conservation: Lessons from the Seychelles. Marine Policy 117: 103921.

https://doi.org/10.1016/j.marpol.2020.103921

Ban, N.C., Frid, A., Reid, M., Edgar, B., Shaw, D., and Siwallace, P. 2018. Incorporate Indigenous perspectives for impactful research and effective management. Nature Ecology \& Evolution 2:1680-1683.

https://doi.org/10.1038/s41559-018-0706-0

Bélisle, A.C., Asselin, H., LeBlanc, P., and Gauthier, S. 2018. Local knowledge in ecological modeling. Ecology and Society 23(2): 14. https://doi.org/10.5751/ES-09949-230214

Berkes, F. 2018. Sacred ecology, 4th ed. New York: Routledge, Taylor \& Francis Group.

Bird, S., Prewer, E., Kutz, S., Leclerc, L.-M., Vilaça, S.T., and Kyle, C.J. 2019. Geography, seasonality, and host-associated population structure influence the fecal microbiome of a genetically depauperate Arctic mammal. Ecology and Evolution 9(23):13202-13217.

https://doi.org/10.1002/ece3.5768 
Bonier, F., Martin, P.R., Moore, I.T., and Wingfield, J.C. 2009. Do baseline glucocorticoids predict fitness? Trends in Ecology \& Evolution 24(11):634-642. https://doi.org/10.1016/j.tree.2009.04.013

Brook, R.K., Kutz, S.J., Veitch, A.M., Popko, R.A., Elkin, B.T., and Guthrie, G. 2009. Fostering community-based wildlife health monitoring and research in the Canadian North. EcoHealth 6(2):266-278. https://doi.org/10.1007/s10393-009-0256-7

Busch, D.S., and Hayward, L.S. 2009. Stress in a conservation context: A discussion of glucocorticoid actions and how levels change with conservation-relevant variables. Biological Conservation 142(12):2844-2853. https://doi.org/10.1016/j.biocon.2009.08.013

Coltman, D.W., O’Donoghue, P., Jorgenson, J.T., Hogg, J.T., Strobeck, C., and Festa-Bianchet, M. 2003. Undesirable evolutionary consequences of trophy hunting. Nature 426(6967):655-658. https://doi.org/10.1038/nature02177

Cuyler, C., Rowell, J., Adamczewski, J., Anderson, M., Blake, J., Bretten, T., Brodeur, V., et al. 2020. Muskox status, recent variation, and uncertain future. Ambio 49:805-819. https://doi.org/10.1007/s13280-019-01205-X

Danielsen, F., Burgess, N.D., Balmford, A., Donald, P.F., Funder, M., Jones, J.P.G., Alviola, P., et al. 2009. Local participation in natural resource monitoring: A characterization of approaches. Conservation Biology 23(1):31 - 42 . https://doi.org/10.1111/j.1523-1739.2008.01063.x

Dantzer, B., Fletcher, Q.E., Boonstra, R., and Sheriff, M.J. 2014. Measures of physiological stress: A transparent or opaque window into the status, management and conservation of species? Conservation Physiology 2(1): cou023.

https://doi.org/10.1093/conphys/cou023

Department of Environment, Government of Nunavut. 2018. 2018/2019 Summary of the Nunavut hunting regulations. Iqaluit: Department of Environment.

https://gov.nu.ca/sites/default/files/2018-2019_nunavut_ hunting_guide.pdf

Di Francesco, J., Navarro-Gonzalez, N., Wynne-Edwards, K., Peacock, S., Leclerc, L.-M., Tomaselli, M., Davison, T., Carlsson, A., and Kutz, S. 2017. Qiviut cortisol in muskoxen as a potential tool for informing conservation strategies. Conservation Physiology 5(1): cox052. https://doi.org/10.1093/conphys/cox052

Dumond, M. 2007. Western Kitikmeot Caribou Workshop. Final Wildlife Report No. 19. Iqaluit: Department of Environment, Government of Nunavut.

https://www.gov.nu.ca/sites/default/files/western $\% 20$ kitikmeot $\% 20$ caribou $\% 20$ workshop $\% 20$ - $\% 20$ final $\% 20$ wildlife\%2019.pdf

ECCC (Environment and Climate Change Canada). 2018. Management plan for the barren-ground caribou (Rangifer tarandus groenlandicus), Dolphin and Union population, in Canada: Adoption of the management plan for the Dolphin and Union caribou (Rangifer tarandus groenlandicus $\mathrm{x}$ pearyi) in the Northwest Territories and Nunavut. Species at Risk Act Management Plan Series. Ottawa: ECCC.
Ewacha, M.V.A., Roth, J.D., Anderson, W.G., Brannen, D.C., and Dupont, D.L.J. 2017. Disturbance and chronic levels of cortisol in boreal woodland caribou. The Journal of Wildlife Management 81(7):1266-1275. https://doi.org/10.1002/jwmg.21288

Ferrell, E.W., Nance, C.N., Torres, A.L., and Torres, S.M. 2014. Using participatory action research to address absenteeism. Action Learning: Research and Practice 11(2):201 - 214. https://doi.org/10.1080/14767333.2014.909184

Fourie, N.H., Turner, T.R., Brown, J.L., Pampush, J.D., Lorenz, J.G., and Bernstein, R.M. 2015. Variation in vervet (Chlorocebus aethiops) hair cortisol concentrations reflects ecological disturbance by humans. Primates 56(4):365-373. https://doi.org/10.1007/s10329-015-0486-y

Gadgil, M., Berkes, F., and Folke, C. 1993. Indigenous knowledge for biodiversity conservation. Ambio 22(2/3):151 - 156 .

Garel, M., Cugnasse, J.-M., Maillard, D., Gaillard, J.-M., Hewison, A.J.M., and Dubray, D. 2007. Selective harvesting and habitat loss produce long-term life history changes in a mouflon population. Ecological Applications 17(6):1607-1618. https://doi.org/10.1890/06-0898.1

Gittelsohn, J., Roache, C., Kratzmann, M., Reid, R., Ogina, J., and Sharma, S. 2010. Participatory research for chronic disease prevention in Inuit communities. American Journal of Health Behavior 34(4):453-464. https://doi.org/10.5993/AJHB.34.4.7

Gray, D.R. 1987. The muskoxen of Polar Bear Pass. Markham, Ontario: Fitzhenry \& Whiteside in trust for the National Museum of Natural Sciences, National Museums of Canada.

Green, J., and Thorogood, N. 2014. Qualitative methods for health research, 3rd ed. London: SAGE Publications.

Gunn, A., and Adamczewski, J. 2003. Muskox Ovibos moschatus. In: Feldhammer, G.A., Thompson, B.C., and Chapman, J.A., eds. Wild mammals of North America: Biology, management, and conservation, 2nd ed. Baltimore, Maryland: The John Hopkins University Press. 1076-1094.

Hall, S.R., Duffy, M.A., and Caceres, C.E. 2005. Selective predation and productivity jointly drive complex behavior in host-parasite systems. The American Naturalist 165(1):70-81. https://doi.org/10.1086/426601

Hanisch, S.L., Riley, S.J., and Nelson, M.P. 2012. Promoting wildlife health or fighting wildlife disease: Insights from history, philosophy, and science. Wildlife Society Bulletin 36(3):477-482. https://doi.org/10.1002/wsb.163

Hanke, A.N., Angohiatok, M., Leclerc, L.-M., Adams, C., and Kutz, S. 2021. A caribou decline foreshadowed by Inuit in the central Canadian Arctic: A retrospective analysis. Arctic 74(4): 437- 455 .

Hansen, B.B., Aanes, R., Herfindal, I., Kohler, J., and Sæther, B.-E. 2011. Climate, icing, and wild Arctic reindeer: Past relationships and future prospects. Ecology 92(10):1917-1923. https://doi.org/10.1890/11-0095.1

Huntington, H.P. 2011. The local perspective. Nature 478:182 - 183. https://doi.org/10.1038/478182a 
Huntington, H., and Fox, S. 2005. The changing Arctic: Indigenous perspectives. In: Symon, C., Arris, L., and Heal, B., eds. Arctic climate impact assessment: Scientific report. Cambridge: Cambridge University Press. 61-98.

Huntington, H.P., Suydam, R.S., and Rosenberg, D.H. 2004. Traditional knowledge and satellite tracking as complementary approaches to ecological understanding. Environmental Conservation 31(3):177-180. https://doi.org/10.1017/S0376892904001559

INAC (Indian and Northern Affairs Canada). 1984. The Western Arctic claim: The Inuvialuit Final Agreement. Ottawa: INAC. https://www.eia.gov.nt.ca/sites/eia/files/inuvialuit_final_ agreement_0.pdf

__ _ 1993. Agreement between the Inuit of the Nunavut Settlement Area and Her Majesty the Queen in right of Canada. Ottawa: INAC.

https://www.tunngavik.com/documents/publications/LAND_ CLAIMS_AGREEMENT_NUNAVUT.pdf

IPCC (Intergovernmental Panel on Climate Change). 2014. Climate change 2014: Impacts, adaptation, and vulnerability. Contribution of Working Group II to the Fifth Assessment Report of the IPCC. Cambridge: Cambridge University Press.

ITK (Inuit Tapiriit Kanatami). 2018. National Inuit strategy on research. Ottawa: ITK.

https://www.itk.ca/national-strategy-on-research-launched/

ITK and NRI (Inuit Tapiriit Kanatami and Nunavut Research Institute). 2006. Negotiating research partnership with Inuit communities: A guide for researchers. Nickels, S., Shirley, J., and Laidler, G., eds. Ottawa: ITK; Iqaluit: NRI.

Janska, E. 2008. Health knowledge, traditional. In: Kirch, W., ed. Encyclopedia of public health. Dordrecht, Netherlands: Springer. 611-614.

Jingfors, K.T. 1982. Seasonal activity budgets and movements of a reintroduced Alaskan muskox herd. The Journal of Wildlife Management 46(2):344-350.

https://doi.org/10.2307/3808645

Koren, L., Whiteside, D., Fahlman, Å., Ruckstuhl, K., Kutz, S., Checkley, S., Dumond, M., and Wynne-Edwards, K. 2012. Cortisol and corticosterone independence in cortisoldominant wildlife. General and Comparative Endocrinology 177(1):113-119. https://doi.org/10.1016/j.ygcen.2012.02.020

Koren, L., Bryan, H., Matas, D., Tinman, S., Fahlman, Å., Whiteside, D., Smits, J., and Wynne-Edwards, K. 2019. Towards the validation of endogenous steroid testing in wildlife hair. Journal of Applied Ecology 56(3):547-561.

https://doi.org/10.1111/1365-2664.13306

Kovach, M. 2009. Indigenous methodologies: Characteristics, conversations, and contexts. Toronto, Ontario: University of Toronto Press.

Kumpula, T., Pajunen, A., Kaarlejärvi, E., Forbes, B.C., and Stammler, F. 2011. Land use and land cover change in Arctic Russia: Ecological and social implications of industrial development. Global Environmental Change 21(2):550-562. https://doi.org/10.1016/j.gloenvcha.2010.12.010
Kutz, S., and Tomaselli, M. 2019. "Two-eyed seeing” supports wildlife health. Science 364(6446):1135-1137.

https://doi.org/10.1126/science.aau6170

Kutz, S., Rowell, J., Adamczewski, J., Gunn, A., Cuyler, C., Aleuy, O.A., Austin, M., et al. 2017. Muskox Health Ecology Symposium 2016: Gathering to share knowledge on Umingmak in a time of rapid change. Arctic 70(2):225-236.

https://doi.org/10.14430/arctic4656

Laforest, B.J., Hébert, J.S., Obbard, M.E., and Thiemann, G.W. 2018. Traditional ecological knowledge of polar bears in the northern Eeyou Marine Region, Québec, Canada. Arctic 71(1):40-58.

https://doi.org/10.14430/arctic4696

Langlois, A., Johnson, C.-A., Montpetit, B., Royer, A., BlukaczRichards, E.A., Neave, E., Dolant, C., et al. 2017. Detection of rain-on-snow (ROS) events and ice layer formation using passive microwave radiometry: A context for Peary caribou habitat in the Canadian Arctic. Remote Sensing of Environment 189:84-95.

https://doi.org/10.1016/j.rse.2016.11.006

Lent, P.C. 1999. Muskoxen and their hunters: A history. Norman: University of Oklahoma Press.

Lubin, D., and Massom, R. 2006. Polar remote sensing. Volume I: Atmosphere and oceans. Berlin: Springer; Chichester: Praxis Publishing Ltd.

Malterud, K., Siersma, V.D., and Guassora, A.D. 2016. Sample size in qualitative interview studies: Guided by information power. Qualitative Health Research 26(13):1753 - 1760.

https://doi.org/10.1177/1049732315617444

Martinez-Levasseur, L.M., Furgal, C.M., Hammill, M.O., and Burness, G. 2017. Challenges and strategies when mapping local ecological knowledge in the Canadian Arctic: The importance of defining the geographic limits of participants' common areas of observations. Polar Biology 40(8):1501 - 1513. https://doi.org/10.1007/s00300-016-2071-2

Mastromonaco, G.F., Gunn, K., McCurdy-Adams, H., Edwards, D.B., and Schulte-Hostedde, A.I. 2014. Validation and use of hair cortisol as a measure of chronic stress in eastern chipmunks (Tamias striatus). Conservation Physiology 2(1): cou055.

https://doi.org/10.1093/conphys/cou055

Maxwell, J.A., and Mittapalli, K. 2010. Realism as a stance for mixed methods research. In: Tashakkori, A., and Teddlie, C., eds. SAGE handbook of mixed methods in social \& behavioral research, 2nd ed. Thousand Oaks, California: SAGE Publications. $145-168$.

https://doi.org/10.4135/9781506335193.n6

Morrow, P. 1990. Symbolic actions, indirect expressions: Limits to interpretations of Yupik society. Études/Inuit/Studies 14(1/2):141 - 158 .

Packer, C., Holt, R.D., Hudson, P.J., Lafferty, K.D., and Dobson, A.P. 2003. Keeping the herds healthy and alert: Implications of predator control for infectious disease. Ecology Letters 6(9):797-802.

https://doi.org/10.1046/j.1461-0248.2003.00500.x 
Patyk, K.A., Duncan, C., Nol, P., Sonne, C., Laidre, K., Obbard, M., Wiig, Ø., et al. 2015. Establishing a definition of polar bear (Ursus maritimus) health: A guide to research and management activities. Science of the Total Environment 514:371-378. https://doi.org/10.1016/j.scitotenv.2015.02.007

Peacock, S.J., Mavrot, F., Tomaselli, M., Hanke, A., Fenton, H., Nathoo, R., Aleuy, O.A., et al. 2020. Linking co-monitoring to co-management: Bringing together local, traditional, and scientific knowledge in a wildlife status assessment framework. Arctic Science 6(3):247-266. https://doi.org/10.1139/as-2019-0019

Polfus, J.L., Manseau, M., Simmons, D., Neyelle, M., Bayha, W., Andrew, F., Andrew, L., Klütsch, C.F.C., Rice, K., and Wilson, P. 2016. Łeghágots'enetę (learning together): The importance of Indigenous perspectives in the identification of biological variation. Ecology and Society 21(2): 18. https://doi.org/10.5751/ES-08284-210218

Post, E., Bhatt, U.S., Bitz, C.M., Brodie, J.F., Fulton, T.L., Hebblewhite, M., Kerby, J., Kutz, S.J., Stirling, I., and Walker, D.A. 2013. Ecological consequences of sea-ice decline. Science 341(6145):519-524. https://doi.org/10.1126/science.1235225

Prno, J., Bradshaw, B., Wandel, J., Pearce, T., Smit, B., and Tozer, L. 2011. Community vulnerability to climate change in the context of other exposure-sensitivities in Kugluktuk, Nunavut. Polar Research 30(1): 7363.

https://doi.org/10.3402/polar.v30i0.7363

QSR International. 2018. NVivo. Burlington, Maine: QSR International.

Raponi, M., Beresford, D.V., Schaefer, J.A., Thompson, I.D., Wiebe, P.A., Rodgers, A.R., and Fryxell, J.M. 2018. Biting flies and activity of caribou in the boreal forest. The Journal of Wildlife Management 82(4):833-839. https://doi.org/10.1002/jwmg.21427

Riseth, J.Å., Tømmervik, H., Helander-Renvall, E., Labba, N., Johansson, C., Malnes, E., Bjerke, J.W., et al. 2011. Sámi traditional ecological knowledge as a guide to science: Snow, ice and reindeer pasture facing climate change. Polar Record 47(3):202-217. https://doi.org/10.1017/S0032247410000434

Robinson, C.J., and Wallington, T.J. 2012. Boundary work: Engaging knowledge systems in co-management of feral animals on Indigenous lands. Ecology and Society 17(2): 16. https://doi.org/10.5751/ES-04836-170216

Roller, M.R., and Lavrakas, P.J. 2015. Applied qualitative research design: A total quality framework approach. New York: The Guilford Press.

Romero, L.M., and Butler, L.K. 2007. Endocrinology of stress. International Journal of Comparative Psychology 20(23):89-95.

Saldaña, J. 2013. The coding manual for qualitative researchers, 2nd ed. Los Angeles: SAGE Publications.
SARC (Species at Risk Committee). 2013. Species status report: Dolphin and Union caribou (Rangifer tarandus groenlandicus $\mathrm{x}$ pearyi) in the Northwest Territories. Yellowknife, Northwest Territories: SARC.

https://www.nwtspeciesatrisk.ca/sites/enr-species-at-risk/files/ dolphin_and_union_caribou_status_and_assessment_2013. pdf

. 2017. Species status report: Grizzly bear (Ursus arctos) in the Northwest Territories. Yellowknife, Northwest Territories: SARC.

Schnarch, B. 2004. Ownership, control, access, and possession (OCAP) or self-determination applied to research: A critical analysis of contemporary First Nations research and some options for First Nations communities. Journal of Aboriginal Health 1(1):80-95. https://doi.org/10.3138/ijih.vli1.28934

Sefa Dei, G.J., Hall, B.L., and Rosenberg, D.G., eds. 2000. Indigenous knowledges in global contexts: Multiple readings of our world. Toronto, Canada: University of Toronto Press.

Stankowich, T. 2008. Ungulate flight responses to human disturbance: A review and meta-analysis. Biological Conservation 141(9):2159-2173. https://doi.org/10.1016/j.biocon.2008.06.026

Statistics Canada. 2016. Census profile, 2016 Census: Kugluktuk, Hamlet [Census subdivision], Nunavut and Nunavut [Territory].

Stephen, C. 2014. Toward a modernized definition of wildlife health. Journal of Wildlife Diseases 50(3):427-430. https://doi.org/10.7589/2013-11-305

Stephens, C., Nettleton, C., Porter, J., Willis, R., and Clark, S. 2005. Indigenous peoples' health — why are they behind everyone, everywhere? The Lancet 366(9479):10-13. https://doi.org/10.1016/S0140-6736(05)66801-8

Tomaselli, M. 2018. Improved wildlife health and disease surveillance through the combined use of local knowledge and scientific knowledge. PhD dissertation, Faculty of Veterinary Medicine, University of Calgary, Calgary, Alberta.

Tomaselli, M., Gerlach, S.C., Kutz, S.J., Checkley, S.L., and the Community of Iqaluktutiaq. 2018a. Iqaluktutiaq voices: Local perspectives about the importance of muskoxen, contemporary and traditional use and practices. Arctic 71(1):1-14. https://doi.org/10.14430/arctic4697

Tomaselli, M., Kutz, S., Gerlach, C., and Checkley, S. 2018b. Local knowledge to enhance wildlife population health surveillance: Conserving muskoxen and caribou in the Canadian Arctic. Biological Conservation 217:337-348. https://doi.org/10.1016/j.biocon.2017.11.010

Tomaselli, M., Elkin, B., Kutz, S., Harms, N.J., Nymo, H.I., Davison, T., Leclerc, L.-M., et al. 2019. A transdisciplinary approach to Brucella in muskoxen of the western Canadian Arctic 1989-2016. EcoHealth 16(3):488-501. https://doi.org/10.1007/s10393-019-01433-3

Tomasini, S. 2018. Unpacking the Red List: Use (and misuse?) of expertise, knowledge, and power. Conservation \& Society 16(4):505-517.

https://doi.org/10.4103/cs.cs_16_52 
Usher,P.J.2000. Traditional ecologicalknowledgeinenvironmental assessment and management. Arctic 53(2):183-193. https://doi.org/10.14430/arctic849

Wild, M.A., Hobbs, N.T., Graham, M.S., and Miller, M.W. 2011. The role of predation in disease control: A comparison of selective and nonselective removal on prion disease dynamics in deer. Journal of Wildlife Diseases 47(1):78-93. https://doi.org/10.7589/0090-3558-47.1.78

Wilson, S. 2008. Research is ceremony: Indigenous research methods. Black Point, Nova Scotia: Fernwood Publishing.

Witter, L.A., Johnson, C.J., Croft, B., Gunn, A., and Gillingham, M.P. 2012. Behavioural trade-offs in response to external stimuli: Time allocation of an Arctic ungulate during varying intensities of harassment by parasitic flies. Journal of Animal Ecology 81(1):284-295.

https://doi.org/10.1111/j.1365-2656.2011.01905.x
Wrona, F.J., Prowse, T.D., and Reist, J.D. 2005. Freshwater ecosystems and fisheries. In: Symon, C., Arris, L., and Heal, B., eds. Arctic climate impact assessment: Scientific report. Cambridge: Cambridge University Press. 353-452.

Ytrehus, B., Bretten, T., Bergsjø, B., and Isaksen, K. 2008. Fatal pneumonia epizootic in musk ox (Ovibos moschatus) in a period of extraordinary weather conditions. EcoHealth 5(2):213 - 223. https://doi.org/10.1007/s10393-008-0166-0

Ytrehus, B., Davidson, R.K., and Isaksen, K. 2015. Single causative factor for severe pneumonia epizootics in muskoxen? EcoHealth 12(3):395-397.

https://doi.org/10.1007/s10393-015-1033-4 